\title{
Trinexapac-Ethyl e AdubaçÃo Nitrogenada na Cultura do Trigo ${ }^{1}$
}

\author{
Trinexapac-Ethyl and Nitrogen Fertilization Rates in Wheat Crop
}

\author{
PAGLIOSA, E.E. ${ }^{2}$, BENIN, G. ${ }^{3}$, BIEZUS, E. ${ }^{2}$, BECHE, E. ${ }^{2}$, SILVA, C.L. ${ }^{2}$, MARCHESE, J.A. ${ }^{3}$ e \\ MARTIN, T.N. ${ }^{4}$
}

\begin{abstract}
RESUMO - O objetivo deste trabalho foi avaliar o efeito de doses do regulador de crescimento trinexapac-ethyl e niveis de adubação nitrogenada sobre o desempenho agronômico e rendimento de grãos de três cultivares de trigo. O delineamento experimental foi de blocos ao acaso, em esquema fatorial, com três repetições, sendo: duas doses de adubação nitrogenada (60 e $120 \mathrm{~kg} \mathrm{ha}^{-1}$ ), três cultivares de trigo (BRS 208, BRS 220 e BRS Guamirim), quatro doses de trinexapac-ethyl (0, 70, 140 e $210 \mathrm{~g}$ i.a. ha-1) e duas safras agricolas (2008 e 2009). Na microrregião de Pato Branco, a dose de $60 \mathrm{~kg}^{-1}$ é suficiente para maximizar o potencial de rendimento de grãos dos cultivares avaliados. Independentemente da estatura dos cultivares, o regulador de crescimento não apresentou efeito positivo sobre o rendimento de grãos, com efeito negativo na presença de menor disponibilidade hídrica.
\end{abstract}

Palavras-chave: Triticum aestivum, rendimento de grãos, regulador de crescimento, nitrogênio.

\begin{abstract}
The objective of this work was to evaluate the effect of trinexapac-ethyl and nitrogen doses on the agronomic performance and grain yield of three wheat cultivars. The experiment was arranged in a randomized block design in a factorial scheme, with three replications. The treatments were two nitrogen fertilization doses (60 and $20 \mathrm{~kg} \mathrm{ha}^{-1}$ ), three wheat cultivars (BRS 208, BRS 220, and BRS Guamirim), fourtrinexapac-ethyl doses (0, 70, 140, and $210 \mathrm{~g}$ a.i. ha $\mathrm{h}^{-1}$ ) and two harvest years (2008 and 2009). In the Pato Branco microregion, the nitrogen rate of $60 \mathrm{~kg} \mathrm{ha}^{-1}$ was sufficient to maximize the yield potential of the evaluated cultivars. Regardless of the height of the cultivar plants, trinexapac-ethyl showed no positive effect on grain yield, with negative effect under waterdeficit stress.
\end{abstract}

Keywords: Triticum aestivum, grain yield, growth regulator, nitrogen.

\section{INTRODUÇÃO}

O interesse em maximizar a produção de trigo tem estimulado a adoção de práticas intensivas de manejo da cultura, em que se destaca a utilização de elevadas doses de adubação nitrogenada. A utilização de reguladores vegetais também vem se tornando cada dia mais uma ferramenta de grande importância para melhorar a eficiência produtiva de várias espécies de plantas.
Na cultura do trigo, a deficiência em nitrogênio afeta a produção de biomassa e eficiência de uso da radiação solar, com grande efeito sobre o rendimento de grãos e seus componentes (Heinemann et al., 2006; Kutman et al., 2011). No Brasil, tradicionalmente, são usados de 30 a $60 \mathrm{~kg} \mathrm{ha}^{-1}$ de nitrogênio, sendo as menores doses utilizadas em solos mais férteis e em sucessão com leguminosas. Pequenas doses limitam a produtividade, e altas doses podem levar ao acamamento,

Recebido para publicação em 8.5.2012 e aprovado em 1.12.2012.

2 Engō-Agr ${ }^{0}$., Mestrando do Programa de Pós-Graduação em Agronomia, Universidade Tecnológica Federal do Paraná - UTFPR, Campus Pato Branco; ${ }^{3}$ Professor, Dr., Curso de Agronomia, - UTFPR, Campus Pato Branco, Via do Conhecimento, Km 01, Caixa Postal 571, 85503-390 Pato Branco-PR, <benin@utfpr.edu.br> ;4 Professor, Dr., Universidade Federal de Santa Maria - UFSM, Santa Maria-RS. 
dificultando a colheita, reduzindo o rendimento e comprometendo a qualidade dos grãos (Rodrigues et al., 2003; Massaroto et al., 2007; Teixeira Filho et al., 2010). Com a utilização de cultivares modernos, tem-se observado máxima resposta no rendimento de grãos de trigo quando as doses de adubação nitrogenada variam de 120 a $185 \mathrm{~kg} \mathrm{ha}^{-1}$ (Trindade et al., 2006; Teixeira Filho et al., 2010).

Assim, a utilização de técnicas de manejo que possibilitem elevar a tolerância ao acamamento passou a ser extremamente importante, uma vez que o acamamento prejudica $o$ rendimento e a qualidade dos grãos do trigo e dificulta a colheita mecanizada (Zagonel \& Fernandes, 2007; Espindula et al., 2010; Teixeira Filho et al., 2010). Nesse sentido, a utilização do trinexapac-ethyl tem se destacado pela eficiência na redução da estatura das plantas e melhoria da arquitetura foliar de trigo e pelo aumento do diâmetro de colmo, diminuindo o acamamento e otimizando o uso da radiação solar, com aumento da produtividade (Zagonel \& Fernandes, 2007).

$\mathrm{O}$ risco de acamamento, associado às boas perspectivas de rendimento de grãos da cultura e às condições climáticas, deve orientar a decisão de aplicação de regulador de crescimento. Segundo a recomendação do fabricante, para a cultura do trigo, a dose recomendada do trinexapac-ethyl é de 100 a 125 g de i.a. ha $^{-1}$, aplicado no estádio entre o primeiro e o segundo nó visível. Essa recomendação é ampla e não distinta em relação ao porte dos cultivares, os quais podem responder de maneira diferente em relação à dose do produto (Rodrigues et al., 2003). Berti et al. (2007) observaram que os cultivares de trigo Supera, CEP-24, Vanguarda e CD-104 apresentaram o melhor desempenho do rendimento de grãos nas doses de 76, 132, 63 e 81 g.i.a. ha ${ }^{-1}$ de trinexapac-ethyl, respectivamente. Essas observações sugerem que o aumento da produtividade pode ser alcançado com o uso de doses abaixo do recomendado.

Cultivares de porte médio a baixo, apesar de menos responsivos ao trinexapac-ethyl, também podem ter seu rendimento de grãos maximizado pela melhor arquitetura foliar e captação da radiação, pelo incremento no número de afilhos férteis e pelo maior direcionamento dos fotoassimilados para a produção de grãos, em detrimento do desenvolvimento do colmo (Zagonel et al., 2002; Matyziak, 2006; Zagonel \& Fernandes, 2007).

Dessa forma, o presente trabalho teve por objetivo avaliar o efeito de doses do regulador de crescimento trinexapac-ethyl e niveis de adubação nitrogenada sobre o desempenho agronômico de três cultivares de trigo de diferentes estaturas de planta e tolerância ao acamamento.

\section{MATERIAL E MÉTODOS}

O experimento foi conduzido nas safras 2008 e 2009 em Pato Branco-PR, situado na latitude de $26^{\circ} 11^{\prime} \mathrm{S}$, longitude de $52^{\circ} 36^{\prime} \mathrm{W}$ e altitude de $760 \mathrm{~m}$. A área utilizada foi cultivada com a cultura de soja (verão) e trigo (inverno), nos últimos três anos, em sistema de plantio direto. O solo é Latossolo Vermelho Distroférrico Úmbrico, textura argilosa (Bhering et al., 2008).

Utilizou-se o delineamento experimental de blocos ao acaso, e os tratamentos foram distribuídos em esquema fatorial em três repetições, com a combinação dos seguintes fatores: a) duas doses de adubação nitrogenada (60 e $120 \mathrm{~kg}$ de nitrogênio ha ${ }^{1}$ ), na forma de ureia ( $45 \%$ de $\mathrm{N})$, aplicadas em cobertura no início do perfilhamento, para a menor dose, e parceladas no início e final do perfilhamento, para a maior dose; b) três cultivares de trigo (BRS 208, BRS 220 e BRS Guamirim); c) quatro doses de trinexapac-ethyl $(0,70,140 \mathrm{e}$ 210 g i.a. ha ${ }^{-1}$ ), correspondente a 0, 280, 560 e $840 \mathrm{~mL} \mathrm{ha}^{-1}$ do produto comercial Moddus; e d) duas safras agrícolas (2008 e 2009).

Os dados referentes à análise de solo dos anos 2008 e 2009 são apresentados na Tabela 1. A coleta do solo foi realizada em uma profundidade de $20 \mathrm{~cm}$. Os dados de precipitação e radiação solar dos anos 2008 e 2009 são apresentados na Figura 1.

A semeadura foi realizada em 5 e 8 de julho de 2008 e 2009, respectivamente, de acordo com o zoneamento agrícola estabelecido pelas recomendações técnicas para a cultura do trigo (Reunião..., 2007, 2008). As parcelas foram compostas de seis linhas de 5,0 m de comprimento, espaçadas de $0,17 \mathrm{~m}$; consideraram-se como área útil as quatro linhas 
Tabela 1 - Resultados de análise química do solo antes da instalação do experimento - 2008 e 2009

\begin{tabular}{|c|c|c|c|c|c|c|c|c|c|c|}
\hline \multirow{3}{*}{ Ano } & \multirow[b]{2}{*}{$\mathrm{pH}^{1 /}$} & \multicolumn{5}{|c|}{ Cátion trocável } & \multirow{3}{*}{$\begin{array}{c}\mathrm{P} \\
\left(\mathrm{mg} \cdot \mathrm{dm}^{-3}\right) \\
\end{array}$} & \multirow{3}{*}{$\begin{array}{c}\text { M.O. } \\
\left(\mathrm{g} \mathrm{dm}^{-3}\right) \\
\end{array}$} & \multirow[b]{2}{*}{$\mathrm{V}$} & \multirow[b]{2}{*}{ M } \\
\hline & & $\begin{array}{c}\mathrm{H}+\mathrm{Al} \\
\mathrm{AAlAl}^{*}\end{array}$ & $\mathrm{Al}^{3+}$ & $\mathrm{Ca}^{2+}$ & $\mathrm{Mg}^{2+}$ & $\mathrm{K}^{+}$ & & & & \\
\hline & $\left(\mathrm{CaCl}^{2}\right)$ & \multicolumn{5}{|c|}{$\left(\mathrm{cmol}^{\left.\mathrm{d} \mathrm{dm}^{-3}\right)}\right.$} & & & \multicolumn{2}{|c|}{$(\%)$} \\
\hline 2008 & 5,10 & 4,28 & 0,00 & 4,37 & 2,54 & 0,35 & 1,19 & 58,80 & 62,9 & 0,0 \\
\hline 2009 & 5,10 & 5,76 & 0,00 & 4,76 & 2,65 & 0,33 & 2,84 & 60,31 & 57,3 & 0,0 \\
\hline
\end{tabular}

${ }^{1 /} \mathrm{pH}$ : potencial de hidrogênio; $\mathrm{H}+\mathrm{Al}$ : acidez potencial; $\mathrm{Al}^{3+}$ : alumínio; $\mathrm{Ca}^{2+}$ : cálcio; $\mathrm{Mg}^{2+}$ : magnésio; $\mathrm{K}^{+}$: potássio; $\mathrm{P}$ : fósforo $(\mathrm{Mehlich}) ; \mathrm{V}$ : saturação por bases; M: saturação por alumínio.

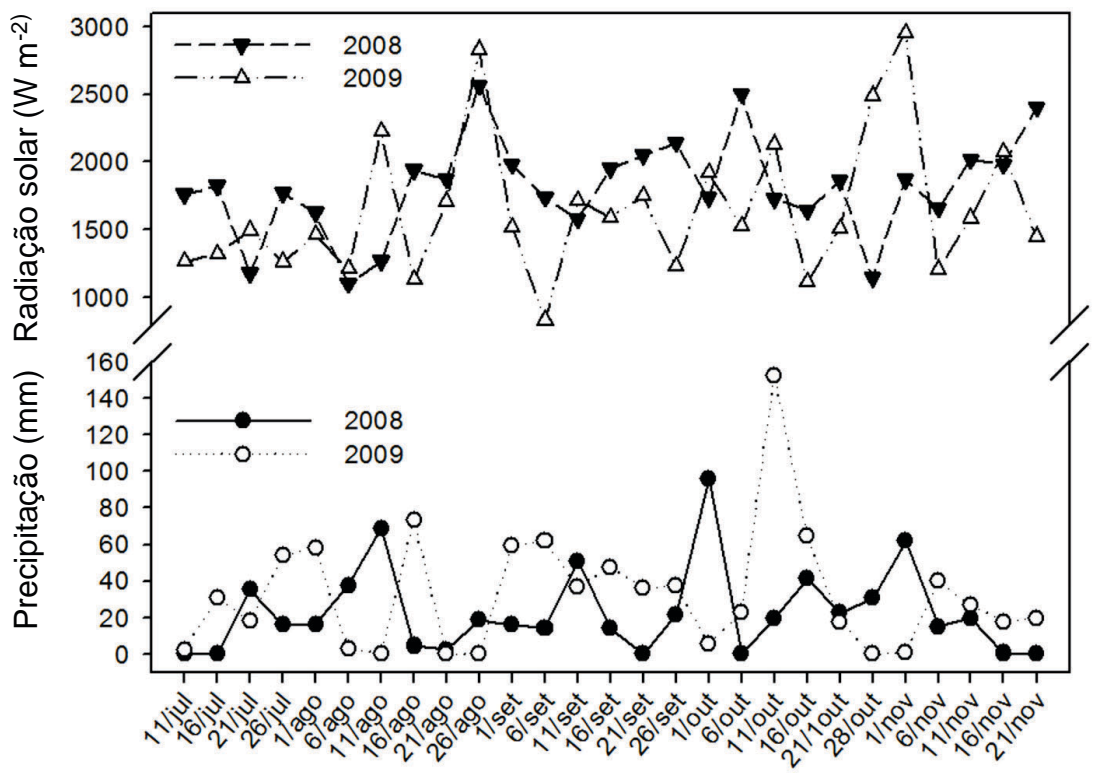

Fonte: IAPAR - Pato Branco-PR.

Figura 1 - Dados de precipitação, radiação e temperatura dos anos de 2008 e 2009, no intervalo de cinco em cinco dias.

centrais. A adubação de base, em ambos os anos, consistiu da aplicação de $24 \mathrm{~kg}$ de nitrogênio ha-1, $60 \mathrm{~kg}$ de $\mathrm{P}_{2} \mathrm{O}_{5}$ ha $^{-1}$ e $60 \mathrm{~kg}$ de $\mathrm{K}_{2} \mathrm{O}$ ha $^{-1}$; a adubação de cobertura com nitrogênio (60 e $120 \mathrm{~kg}$ de nitrogênio $\mathrm{ha}^{-1}$ ) foi somada à adubação de base. A densidade de semeadura foi de 350 sementes aptas por $\mathrm{m}^{2}$. $\mathrm{O}$ controle de plantas daninhas foi feito com o herbicida iodosulfuron-metil, e as doenças, controladas através da aplicação de fungicida à base de triazol + estrobirulina, no surgimento dos primeiros sintomas de patógenos.

O trinexapac-ethyl foi aplicado com pulverizador costal com $\mathrm{CO}_{2}$ comprimido, à pressão constante de $30 \mathrm{lb} \mathrm{pol}^{-2}$, com bicos de jato plano tipo leque XR 110-02, entre o primeiro e o segundo nó visível, correspondente aos estádios 31 a 32 da escala de Zadoks et al. (1974), com volume de calda de 200 litros por hectare. Foram avaliados seis caracteres agronômicos: número de afilhos férteis por metro linear (NAF); estatura de planta, em cm (EP); número de grãos por espiga (NGE); massa de mil grãos, em gramas (MMG); peso do hectolitro, em $\mathrm{kg} \mathrm{hL}^{-1}(\mathrm{PH})$; e rendimento de grãos, em kg ha-1 (RG).

Os dados foram submetidos à análise de homogeneidade de variância (teste de Bartllet) e de normalidade (Lilliefors). Posteriormente, os dados foram submetidos à análise de variância conjunta no modelo polifatorial, considerandose o efeito de genótipo, doses de nitrogênio e de trinexapac-ethyl como fixo e de ano como aleatório. As médias de cultivares e doses de 
adubação nitrogenada foram comparadas por meio do teste de Tukey a $5 \%$ de probabilidade de erro. Para o fator doses de regulador de crescimento, realizou-se análise de regressão polinomial. A escolha do modelo considerou as equações com melhores ajustes, confirmados pela significância dos coeficientes de regressão do teste F e do teste t de Student a 5 e 10\% de probabilidade de erro, respectivamente. Os valores de máxima eficiência técnica das doses de regulador de crescimento foram calculados a partir da primeira derivação da equação polinomial quadrática, igualando a equação a zero. As análises foram realizadas utilizando os programas $\mathrm{R}$ ( $\mathrm{R}$ Development Core Team, 2010) e Genes (Cruz, 2006), e os gráficos, construídos pelo Sigmaplot 11.0.

\section{RESULTADOS E DISCUSSÃO}

A análise da variância não evidenciou significância da interação quádrupla para os parâmetros avaliados. O caractere MMG foi o único que evidenciou significância apenas para o fator principal de dose de trinexapacethyl. Os coeficientes de variação obtidos conferiram boa precisão experimental (Tabela 2).

As doses de nitrogênio e os anos de avaliação alteraram o desempenho dos caracteres avaliados (Tabela 3). A dose de $60 \mathrm{~kg} \mathrm{ha}^{-1}$ de nitrogênio $(\mathrm{N})$ conferiu maior peso do hectolitro $(73,45)$ em comparação à dose de $120 \mathrm{~kg} \mathrm{ha}^{-1}$ $(72,08)$. Os valores de $\mathrm{PH}$ foram maiores no ano de $2009(74,07)$ em comparação a $2008(71,19)$, provavelmente devido à maior disponibilidade hídrica (Figura 1). Também, na safra agrícola de 2009, houve maior incidência de radiação no período de enchimento de grãos.

O cultivar BRS Guamirim apresentou maiores valores de NAF (133) e a menor estatura de planta $(65 \mathrm{~cm})$, sendo BRS 208 o de maior estatura $(81 \mathrm{~cm})$. Os maiores valores de

Tabela 2 - Análise de variância conjunta com as respectivas fontes de variação (FV), graus de liberdade (GL) e quadrados médios $(\mathrm{QM})$ para as variáveis massa de mil grãos $(\mathrm{MMG})$, peso do hectolitro $(\mathrm{PH})$, número de afilhos férteis (NAF), número de grãos por espiga (NGE), estatura de planta (EP) e rendimento de grãos (RG), incluindo média geral e coeficiente de variação, em dois anos de avaliação (2008 e 2009), com duas doses de nitrogênio (60 e $120 \mathrm{~kg} \mathrm{ha}^{-1}$ ) em três genótipos de trigo (BRS 208, BRS 220 e BRS Guamirim), em função de quatro doses de redutor de crescimento $(0,70,140$ e 210 g.i.a. ha-1 $)$

\begin{tabular}{|c|c|c|c|c|c|c|c|}
\hline \multirow{2}{*}{ Fonte de variação } & \multirow{2}{*}{ G.L. } & \multicolumn{6}{|c|}{ Q.M. } \\
\hline & & MMG & $\mathrm{PH}$ & NAF & NGE & EP & RG \\
\hline (B1/ano) & 4 & 0,2 & 2,1 & 261,6 & 65,7 & 45,1 & 323030 \\
\hline $\operatorname{Anos}(\mathrm{A})$ & 1 & $0,0^{\mathrm{ns}}$ & $299,1^{* *}$ & $738,0^{* * *}$ & $1572,9^{* *}$ & $2272,1^{* * *}$ & 8349297 \\
\hline Cultivares (C) & 2 & 9,3 ns & $284,1^{\text {ns }}$ & $24871,9^{* * *}$ & $1130,8^{* *}$ & $3159,7^{* *}$ & $111152^{\mathrm{ns}}$ \\
\hline Doses de Nitrogênio (N) & 1 & 19,5 ns & $42,2^{*}$ & 2652,3 ns & $13,4^{\mathrm{ns}}$ & 37,6 ns & $2503642^{* * *}$ \\
\hline Doses de Redutor (R) & 3 & $28,1^{* * *}$ & $109,5^{* *}$ & $1142,5^{\text {** }}$ & $71,3^{* *}$ & $2840,3^{* *}$ & $13636999^{\mathrm{ns}}$ \\
\hline $\mathrm{A} \times \mathrm{C}$ & 2 & $28,2^{\mathrm{ns}}$ & $17,1^{\mathrm{ns}}$ & $10,2^{\mathrm{ns}}$ & 2,2 ns & $1,4^{\mathrm{ns}}$ & $310244^{\text {*** }}$ \\
\hline $\mathrm{A} \times \mathrm{N}$ & 1 & $31,1^{\mathrm{ns}}$ & $3,4^{\mathrm{ns}}$ & $93,4^{* *}$ & $6,0^{\mathrm{ns}}$ & $33,64^{*}$ & $63371^{\text {ns }}$ \\
\hline $\mathrm{N} \times \mathrm{C}$ & 2 & $0,8^{\mathrm{ns}}$ & $17,3^{\mathrm{ns}}$ & $54,8^{\mathrm{ns}}$ & $4,9^{\mathrm{ns}}$ & $8,2^{\text {ns }}$ & $595686^{* * *}$ \\
\hline $\mathrm{A} \times \mathrm{R}$ & 3 & $15,1^{\mathrm{ns}}$ & $47,4^{\mathrm{ns}}$ & $570,3^{* *}$ & $34,6^{*}$ & $735,7^{\text {*** }}$ & $1163109^{* * *}$ \\
\hline $\mathrm{C} \times \mathrm{R}$ & 6 & $6,7 \quad \mathrm{~ns}$ & $39,3^{* *}$ & $157,5^{\mathrm{ns}}$ & $51,2^{* *}$ & $16,3^{\mathrm{ns}}$ & $394969^{* * *}$ \\
\hline $\mathrm{N} \times \mathrm{R}$ & 3 & 4,1 ns & $2,2 \mathrm{~ns}$ & 270,5 ns & 7,0 ns & $11,7^{\mathrm{ns}}$ & $229752^{\mathrm{ns}}$ \\
\hline $\mathrm{A} \times \mathrm{N} \times \mathrm{C}$ & 2 & 1,3 ns & 3,3 ns & $342,5 \quad \mathrm{~ns}$ & 3,4 ns & $13,1^{\mathrm{ns}}$ & $1174600^{* * *}$ \\
\hline $\mathrm{A} \times \mathrm{C} \times \mathrm{R}$ & 6 & $2,5 \mathrm{~ns}$ & $16,8^{\mathrm{ns}}$ & $106,1 \quad \mathrm{~ns}$ & $22,9^{\mathrm{ns}}$ & $4,4^{\mathrm{ns}}$ & $460902^{* * *}$ \\
\hline$A \times N \times R$ & 3 & 11,2 ns & 4,4 ns & 199,1 ns & $59,9^{* *}$ & 7,3 ns & $66955^{\mathrm{ns}}$ \\
\hline $\mathrm{N} \times \mathrm{C} \times \mathrm{R}$ & 6 & $5,6 \mathrm{~ns}$ & $2,7 \mathrm{~ns}$ & $223,5 \mathrm{~ns}$ & $8,3 \mathrm{~ns}$ & $4,5 \mathrm{~ns}$ & $121946^{\mathrm{ns}}$ \\
\hline$A \times N \times C \times R$ & 6 & 6,3 ns & $10,4^{\mathrm{ns}}$ & 82,9 ns & $6,4^{\mathrm{ns}}$ & 2,3 ns & $86518^{\mathrm{ns}}$ \\
\hline Resíduo & 92 & 6,5 & 8,8 & 104,8 & 12,7 & 12,1 & 108082 \\
\hline Medias & & 32,8 & 72,6 & 107,5 & 38,7 & 74,3 & 3882,16 \\
\hline $\mathrm{CV}(\%)$ & & 7,8 & 4,1 & 3,2 & 9,2 & 4,6 & 8,46 \\
\hline
\end{tabular}

$* ; * *$ e ${ }^{\text {ns: }}$ significativo a $5 \%(\mathrm{p}<0,05), 1 \%(\mathrm{p}<0,01)$ e não significativo $(\mathrm{p}>0,05)$ pelo teste $\mathrm{F}$, respectivamente. 
Tabela 3 - Valores médios de peso do hectolitro em duas doses de nitrogênio e em dois anos de avaliação. Médias para número de afilhos férteis e estatura de plantas para três genótipos de trigo e médias para número de afilhos férteis e estatura de plantas em dois anos de avaliação, em função de duas doses de nitrogênio. Média do rendimento de grãos para os anos de 2008 e 2009 , para três cultivares de trigo em duas doses de nitrogênio

\begin{tabular}{|c|c|c|c|c|}
\hline & \multicolumn{4}{|c|}{ Peso do hectolitro } \\
\hline $60 \mathrm{~kg} \mathrm{ha}^{-1} \mathrm{de} \mathrm{N}$ & \multicolumn{2}{|c|}{$74 a^{*}$} & Ano 2008 & $71 \mathrm{~b}$ \\
\hline $120 \mathrm{~kg} \mathrm{ha}^{-1}$ de $\mathrm{N}$ & \multicolumn{2}{|c|}{$72 \mathrm{~b}$} & Ano 2009 & $74 \mathrm{a}$ \\
\hline & \multicolumn{2}{|c|}{ Número de afilhos férteis } & \multicolumn{2}{|c|}{ Estatura de planta $(\mathrm{cm})$} \\
\hline BRS 208 & \multicolumn{2}{|c|}{$95 \mathrm{~b}$} & \multicolumn{2}{|c|}{$81 \mathrm{a}$} \\
\hline BRS 220 & \multicolumn{2}{|c|}{$93 \mathrm{~b}$} & \multicolumn{2}{|c|}{$75 \mathrm{~b}$} \\
\hline \multirow[t]{3}{*}{ BRS Guamirim } & \multicolumn{2}{|c|}{$133 \mathrm{a}$} & \multicolumn{2}{|c|}{$65 \mathrm{c}$} \\
\hline & \multicolumn{2}{|c|}{ Número de afilhos férteis } & \multicolumn{2}{|c|}{ Estatura de planta $(\mathrm{cm})$} \\
\hline & $60 \mathrm{~kg} \mathrm{ha}^{-1} \mathrm{de} \mathrm{N}$ & $120 \mathrm{~kg} \mathrm{ha}^{-1}$ de $\mathrm{N}$ & $60 \mathrm{~kg} \mathrm{ha}^{-1} \mathrm{de} \mathrm{N}$ & $120 \mathrm{~kg} \mathrm{ha}^{-1} \mathrm{de} \mathrm{N}$ \\
\hline Ano 2008 & $100 \mathrm{bB} * *$ & $110 \mathrm{aA}$ & $70 \mathrm{bA}$ & $70 \mathrm{bA}$ \\
\hline \multirow[t]{3}{*}{ Ano 2009} & $106 \mathrm{aB}$ & $113 \mathrm{aA}$ & $77 \mathrm{aB}$ & $79 \mathrm{aA}$ \\
\hline & \multicolumn{4}{|c|}{ Rendimento de grãos em 2008} \\
\hline & BRS 208 & & 220 & BRS Guamirim \\
\hline $60 \mathrm{~kg} \mathrm{ha}^{-1} \mathrm{de} \mathrm{N}$ & $3791 \mathrm{aA}^{* *}$ & & $8 \mathrm{aB}$ & $3395 \mathrm{aA}$ \\
\hline \multirow[t]{3}{*}{$120 \mathrm{~kg} \mathrm{ha}^{-1} \mathrm{de} \mathrm{N}$} & $3521 \mathrm{aA}$ & & $7 \mathrm{aA}$ & $3803 \mathrm{aA}$ \\
\hline & \multicolumn{4}{|c|}{ Rendimento de grãos em 2009} \\
\hline & BRS 208 & & 220 & BRS Guamirim \\
\hline $60 \mathrm{~kg} \mathrm{ha}^{-1} \mathrm{de} \mathrm{N}$ & $3967 \mathrm{aA}^{* *}$ & & $5 \mathrm{aB}$ & $4173 \mathrm{aA}$ \\
\hline $120 \mathrm{~kg} \mathrm{ha}^{-1} \mathrm{de} \mathrm{N}$ & $4311 \mathrm{aA}$ & & $1 \mathrm{aA}$ & $4309 \mathrm{aA}$ \\
\hline
\end{tabular}

* Letras minúsculas idênticas nas colunas não diferem estatisticamente entre si pelo teste de Tukey a $5 \%$ de probabilidade. ** Letras idênticas, minúsculas nas colunas e maiúsculas nas linhas, não diferem estatisticamente entre si pelo teste de Tukey a 5\% de probabilidade.

NAF e EP foram observados em 2009 (Tabela 3). Em ambos os anos, a maior média do NAF foi obtida na dose de $120 \mathrm{~kg} \mathrm{ha}^{-1}$, evidenciando que o nitrogênio é essencial para a emissão e sobrevivência dos afilhos (Almeida \& Mundstock, 1998). Os menores valores de PH observados em condições de maior disponibilidade de adubação nitrogenada se devem à maior competição por nutrientes e fotoassimilados (Coelho et al., 1998).

Em ambos os anos e para todos os cultivares avaliados, não houve incremento significativo no RG em resposta à dose de adubação nitrogenada (Tabela 3). Penckowski et al. (2009) testaram doses desde 90 até $225 \mathrm{~kg}$ de $\mathrm{N} \mathrm{ha}^{-1}$ e também concluíram que a menor dose foi suficiente para garantir produtividade da cultura. Zagonel \& Fernandes (2007) também não obtiveram resposta em produtividade do cultivar Ônix para as diferentes doses de $\mathrm{N}$ (50 e $240 \mathrm{~kg} \mathrm{ha}^{-1}$ ), atribuindo esse resultado ao suprimento adequado fornecido pela menor dose de $\mathrm{N}$, aliado ao alto teor de matéria orgânica do solo. Resultados semelhantes também foram observados por Massaroto et al. (2007). Segundo Wiethölter (1996), a soja, sucedendo a cultura do trigo, pode contribuir com 17 a $59 \mathrm{~kg} \mathrm{ha}^{-1}$ de N.

Com $60 \mathrm{~kg} \mathrm{ha}^{-1}$ de N, os maiores rendimentos foram obtidos para os cultivares BRS 208 (3.791 kg ha ${ }^{-1}$ ) em 2008 e BRS Guamirim (4.173 $\mathrm{kg} \mathrm{ha}^{-1}$ ) em 2009 (Tabela 3). Esses resultados indicam diferenças no potencial genético dos cultivares em resposta às doses de nitrogênio avaliadas e o efeito do ano agrícola sobre a expressão do potencial de rendimento de grãos e aproveitamento do $\mathrm{N}$ aplicado - resultados semelhantes foram observados por Felício et al. (2001).

Em 2008, o NAF apresentou incremento linear às doses de trinexapac-ethyl (Figura 2A), porém com ausência de resposta em 2009. Zagonel et al. (2002) também verificaram que a aplicação de trinexapacethyl promoveu efeito positivo no número de espigas por metro linear. Contrariamente, Zagonel \& Fernandes (2007) não observaram 

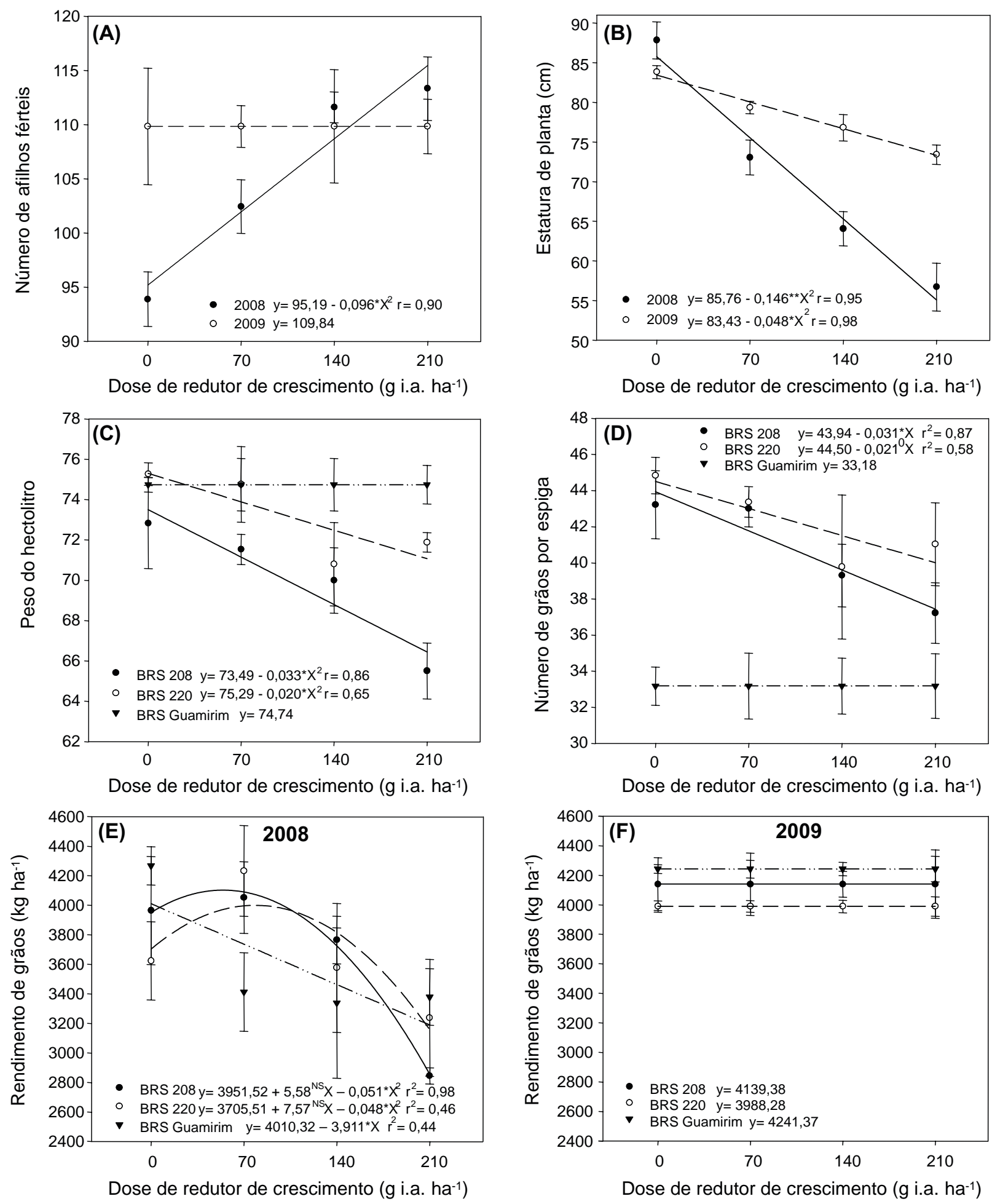

ns $, \stackrel{0}{*}, * * *$ : não significante, significante a 10,5 e $1 \%$, pelo teste $\mathrm{T}$, respectivamente.

Figura 2 - A e B: análise da regressão para número de afilhos férteis e estatura de planta em dois anos de avaliação e em quatro doses de trinexapac-ethyl. C e D: análise de regressão para peso do hectolitro e número de grãos por espiga de três cultivares de trigo em quatro doses de trinexapaque-etílico. E e F: análise de regressão para rendimento de grãos em dois anos de avaliação para três cultivares de trigo em quatro doses de redutor de crescimento. 
efeito do trinexapac-ethyl sobre o número de espigas por metro quadrado em três cultivares de trigo. Em campo, os efeitos do ambiente relacionados à emissão e ao desenvolvimento de afilhos de trigo são dependentes das condições meteorológicas, do genótipo e da condição nutricional da planta (Anjos \& Nery, 2005; Valério et al., 2009).

Houve redução linear na EP (Figura 2B) com o aumento da dose de trinexapac-ethyl. A eficácia desse herbicida em reduzir a estatura de plantas de trigo também foi observada por Matysiak (2006). A redução da estatura foi mais acentuada em 2008, comparado com 2009 , em razão da menor disponibilidade hídrica, cujos valores de precipitação acumulada foram de 626 e $888 \mathrm{~mm}$, respectivamente (Figura 1). Segundo Rodrigues et al. (2003), a deficiência hídrica provoca redução do crescimento e, consequentemente, da estatura da planta, provocando efeito semelhante ao do redutor de crescimento. Estes autores indicam que, em anos de perspectiva de baixa precipitação pluvial, deve-se evitar a aplicação do trinexapac-ethyl.

Em trigo, a manutenção do rendimento de grãos é atribuída à compensação dos seus principais componentes: número de espigas por unidade de área, número de grãos por espiga e massa média do grão (Holen et al., 2001). Nesse contexto, embora as maiores doses de trinexapac-ethyl tenham contribuído para o aumento do NAF em 2008, elas afetaram negativamente o PH e NGE (Figura 2C, D), reduzindo o rendimento de grãos.

$\mathrm{Na}$ ausência de aplicação de regulador de crescimento, o melhor desempenho de RG foi observado para o cultivar BRS Guamirim, em 2008 (Figura 2E). A máxima eficiência técnica do regulador de crescimento para RG foi nas doses de 54,7 e 78,8 g i.a. ha ${ }^{-1}$, para os cultivares BRS 208 e BRS 220 respectivamente. Entretanto, esses incrementos não foram significativos; a partir dessas doses, a redução do rendimento de grãos ocorreu devido à deficiência hídrica. Assim, há indicativo de que a dose de trinexapac-ethyl deve ser ajustada a cada cultivar, sobretudo em genótipos com maior resistência (Berti et al., 2007). Em 2009, a aplicação de trinexapac-ethyl não afetou o RG nos cultivares avaliados (Figura $2 \mathrm{~F}$ ).
Matisyak (2006) também verificou respostas dependentes das condições meteorológicas, especialmente da precipitação pluvial e da temperatura.

Na microrregião de Pato Branco, a dose de $60 \mathrm{~kg} \mathrm{ha}{ }^{-1}$ de $\mathrm{N}$ foi suficiente para a potencialização de rendimento de grãos dos cultivares de trigo avaliados. As limitações climáticas para a expressão do potencial de rendimento de grãos e os elevados níveis de matéria orgânica no solo possivelmente contribuíram para esse resultado (Massaroto et al., 2007).

Durante a condução do experimento, não foi constatada a ocorrência de acamamento. Um maior número de anos, cultivares e locais de experimentação é necessário para uma indicação mais efetiva das doses de adubação nitrogenada e de trinexapac-ethyl a serem aplicadas.

\section{LITERATURA CITADA}

ALMEIDA, M. L.; MUNDSTOCK, C. M. O afilhamento em comunidades de cereais de estação fria é afetado pela qualidade da luz? Ci. Rural, v. 28, n. 3, p. 511-519, 1998.

ANJOS, I. B.; NERY, J. T. Variáveis meteorológicas associadas ao rendimento de grãos no Estado do Paraná. Acta Sci. Agron., v. 27, n. 1, p. 133-144, 2005.

BERTI, M. et al. Produtividade de cultivares de trigo em função do trinexapac-ethyl e doses de nitrogênio. Sci. Agr., v. 8, n. 2, p. 127-134, 2007.

BHERING, S. B. et al. Mapa de solos do Estado do Paraná: legenda atualizada. Rio de Janeiro: Embrapa/Iapar, 2008. 74 p.

COELHO, M. A. O. et al. Resposta da produtividade de grãos e outras características agronômicas do trigo Embrapa22 irrigado ao nitrogênio em cobertura. R. Bras. Ci. Solo, v. 22, n. 3 , p. $555-561,1998$.

CRUZ, C. D. Programa GENES: aplicativo computacional em genética e estatística versão Windows. Viçosa, MG: Universidade Federal de Viçosa, 2006. 442 p.

ESPINDULA, M. C. Efeitos de reguladores de crescimento na elongação do colmo de trigo do colmo de trigo. Acta Sci.

Agron., v. 32, n. 1, p. 109-116, 2010.

FELICIO, J. C. et al. Influência do ambiente no rendimento e na qualidade de grãos de genótipos de trigo com irrigação por aspersão no Estado de São Paulo. Bragantia, v. 60, n. 2, p. $111-120,2001$.

Planta Daninha, Viçosa-MG, v. 31, n. 3, p. 623-630, 2013 
HEINEMANN, A. B. et al. Eficiência de uso da radiação solar na produtividade de trigo decorrente da adubação nitrogenada R. Bras. Eng. Agríc. Amb., v. 10, n. 2, p. 352-356, 2006.

HOLEN, D. L. et al. Response of winter wheat to simulated stand reduction. Agron. J., v. 93, n. 2, p. 364-370, 2001.

KUTMAN, U. B. et al. Effect of nitrogen on uptake, remobilization and partitioning of zinc and iron throughout the development of durum wheat. Plant Soil, v. 342, n. 1-2, p. 149-164, 2011.

MATYSIAK, K. Influence of trinexapac-ethyl on growth and development of winter wheat. J. Plant Protec. Res., v. 46, n. 2 , p. $133-143,2006$.

MASSAROTO, J. A. et al. Comportamento de cultivares de trigo sob diferentes doses de adubação para manutenção de plantio no Brasil Central. R. Ceres, v. 54, n. 314, p. 362-366, 2007.

PENCKOWSKI, L. H. et al. Nitrogênio e redutor de crescimento em trigo de alta produtividade. Acta Sci. Agron., v. 31, n. 3 , p. $473-479,2009$

REUNIÃO DA COMISSÃO BRASILEIRA DE PESQUISA DE TRIGO E TRITICALE. Informações técnicas para a safra 2008: trigo e triticale. Londrina: Embrapa Soja, 2007. 147 p. (Embrapa Soja. Documentos, 301).

REUNIÃO DA COMISSÃO BRASILEIRA DE PESQUISA DE TRIGO E TRITICALE. Informações técnicas para a safra 2009: trigo e triticale. Passo Fundo: Comissão Brasileira de Pesquisa de Trigo, 2008. 172 p
R DEVELOPMENT CORE TEAM. R: A language and environment for statistical computing. Vienna: $\mathrm{R}$ Foundation for Statistical Computing, 2010

RODRIGUES, O. et al. Redutores de crescimento. Passo Fundo: Embrapa Trigo, 2003. (Circular Técnica, 14).

TEIXEIRA FILHO, M. C. M. et al. Doses, fontes e épocas de aplicação de nitrogênio em trigo irrigado em plantio direto Pesq. Agropec. Bras., v. 45, n. 8, p. 797-804, 2010.

TRINDADE, M. G. et al. Nitrogênio e água como fatores de produtividade do trigo no cerrado. R. Bras. Eng. Agríc. Amb. v. 10, n. 1, p. 24-29, 2006.

VALÉRIO, I. P. et al. Fatores relacionados à produção e desenvolvimento de afilhos em trigo. Semina: ciências agrárias, v. 30, n. 1, p. 1207-1218, 2009.

WIETHÖLTER, S. Adubação nitrogenada no sistema plantio direto. Passo Fundo: Embrapa-CNPT, 1996. 44 p.

ZADOKS, J. C. et al. A decimal code for the growth stages of cereals. Weed Res., v. 14, n. 6, p. 415-421, 1974.

ZAGONEL, J. et al. Doses de nitrogênio e densidades de plantas com e sem um regulador de crescimento afetando o trigo, cultivar or-1. Ci. Rural, v. 32, n. 1, p. 25-29, 2002

ZAGONEL, J.; FERNANDES, E. C. Doses e épocas de aplicação de redutor de crescimento afetando cultivares de trigo em duas doses de nitrogênio. Planta Daninha, v. 25, n. 2, p. 331-339, 2007. 